\title{
Recognition motifs rather than phylogenetic origin influence the ability of targeting peptides to import nuclear-encoded recombinant proteins into rice mitochondria
}

\author{
Can Baysal • Ana Pérez-González • Álvaro Eseverri • Xi Jiang • \\ Vicente Medina $\cdot$ Elena Caro $\cdot$ Luis Rubio $\cdot$ Paul Christou $\cdot$ Changfu Zhu
}

Received: 12 July 2019/Accepted: 1 October 2019/Published online: 10 October 2019

(C) The Author(s) 2019

\begin{abstract}
Mitochondria fulfil essential functions in respiration and metabolism as well as regulating stress responses and apoptosis. Most native mitochondrial proteins are encoded by nuclear genes and are imported into mitochondria via one of several receptors that recognize $\mathrm{N}$-terminal signal peptides. The targeting of recombinant proteins to mitochondria therefore requires the presence of an appropriate $\mathrm{N}$-terminal peptide, but little is known about mitochondrial import in monocotyledonous plants such as rice (Oryza sativa). To gain insight into this
\end{abstract}

Electronic supplementary material The online version of this article (https://doi.org/10.1007/s11248-019-00176-9) contains supplementary material, which is available to authorized users.

C. Baysal · V. Medina · P. Christou · C. Zhu ( $\square)$ Department of Plant Production and Forestry Science, University of Lleida-Agrotecnio Center, Av. Alcalde Rovira Roure, 191, 25198 Lleida, Spain e-mail: zhu@pvcf.udl.cat

A. Pérez-González · Á. Eseverri · X. Jiang ·

E. Caro · L. Rubio

Centre for Plant Biotechnology and Genomics, Universidad Politécnica de Madrid (UPM) - Instituto

Nacional de Investigación y Tecnología Agraria y Alimentaria (INIA), Campus Montegancedo UPM, 28223 Pozuelo de Alarcón, Madrid, Spain

P. Christou

ICREA, Catalan Institute for Research and Advanced Studies, Passeig Lluís Companys 23, 08010 Barcelona, Spain phenomenon, we targeted nuclear-encoded enhanced green fluorescent protein (eGFP) to rice mitochondria using six mitochondrial pre-sequences with diverse phylogenetic origins, and investigated their effectiveness by immunoblot analysis as well as confocal and electron microscopy. We found that the ATPA and COX4 (Saccharomyces cerevisiae), SU9 (Neurospora crassa), pFA (Arabidopsis thaliana) and OsSCSb (Oryza sativa) peptides successfully directed most of the eGFP to the mitochondria, whereas the MTS2 peptide (Nicotiana plumbaginifolia) showed little or no evidence of targeting ability even though it is a native plant sequence. Our data therefore indicate that the presence of particular recognition motifs may be required for mitochondrial targeting, whereas the phylogenetic origin of the pre-sequences probably does not play a key role in the success of mitochondrial targeting in dedifferentiated rice callus and plants.

Keywords Subcellular targeting - Mitochondrial pre-sequence $\cdot$ Mitochondrial protein $\cdot$ Protein sorting $\cdot$ Green fluorescent protein

\section{Introduction}

The proteins synthesized by eukaryotic cells are targeted to particular subcellular compartments. In the absence of specific targeting signals, nascent proteins accumulate by default in the cytosol (Kim and 
Hwang 2013). Proteins carrying an N-terminal signal peptide recognized by a signal recognition particle (SRP) on the surface of the endoplasmic reticulum (ER) are co-translationally imported into the secretory pathway, from where they can be routed to various other compartments including the nucleus (Luirink and Sinning 2004; Akopian et al. 2013). Proteins carrying other types of N-terminal or C-terminal peptides are directed post-translationally to peroxisomes, mitochondria or (in plants) to the plastids (Egea et al. 2005). Whereas most organelles are thought to have originated ultimately from the plasma membrane during eukaryote evolution, the mitochondria and plastids are exceptional because they evolved independently from endosymbionts and therefore carry their own genomes (Dolezal et al. 2006). Accordingly, mitochondrial and plastid proteins can be derived either from the organelle genome or the nuclear genome, hence the need for protein import pathways for nuclear-encoded proteins (Chacinska et al. 2009; Endo et al. 2011).

Mitochondria carry out multiple essential functions in the eukaryotic cell, including the generation of ATP by oxidative phosphorylation, the biosynthesis of amino acids and lipids, and the regulation of apoptosis (Rasmusson et al. 2004; Sluse et al. 2006). Approximately $98 \%$ of the enzymes and other proteins required for mitochondrial functions are encoded by the nuclear genome and the remainder by the mitochondrial genome (Taylor and Pfanner 2004). Proteins encoded by the nuclear genome must therefore be imported into the mitochondria, and accordingly the pre-proteins carry $\mathrm{N}$-terminal peptides that are recognized by the hydrophobic binding pockets of the receptor Tom20 (Yamamoto et al. 2011). The targeting peptides are cleaved off by mitochondrial peptidases during or after import, yielding the mature protein (Brix et al. 1997; Obita et al. 2003; Taylor and Pfanner 2004; Mukhopadhyay et al. 2006; Wiedemann and Pfanner 2017).

The targeting of recombinant proteins to plant mitochondria could be useful when the aim is to modulate a mitochondrial function such as energy generation, iron-sulfur cluster assembly, developmental signals, or responses to biotic and abiotic stress (Pierrel et al. 2007; Atkin and Macherel 2009). Furthermore, the low-oxygen mitochondrial environment is ideal for metabolic engineering with oxygensensitive enzymes (Curatti and Rubio 2014; López-
Torrejón et al. 2016) and the control of enzyme metalation, given the abundance of copper, iron, manganese and zinc in the mitochondrial matrix (Pierrel et al. 2007; Pérez-González et al. 2017). However, one of the challenges involved in mitochondrial targeting is the complex structure of the organelle, which features a double membrane separated by an inner matrix, and folded internal cristae separated by a further membrane, allowing the localization and separation of proteins that require specific environments for their activity (Lill and Mühlenhoff 2008). Nuclear-encoded mitochondrial proteins may therefore feature complex targeting peptides up to 90 amino acids in length carrying the information needed for precise localization within mitochondrial compartments or membranes (Huang et al. 2009b). The presequences comprise different groups of amino acids with distinct physicochemical properties and/or mitochondrial outer membrane recognition motifs (Fukasawa et al. 2015). These properties determine the ultimate destination of native and heterologous proteins within the various spaces and membranes of the mitochondrion (Dudek et al. 2013).

The direct experimental analysis of the plant mitochondrial proteome has been carried out predominantly in dicot species such as Arabidopsis (Kruft et al. 2001; Heazlewood et al. 2004; Lee et al. 2012), tobacco (Huang et al. 1990; Allen et al. 2017) and pea (Bardel et al. 2002). In contrast, only a few reports have described the mitochondrial proteome of monocot species such as rice (Heazlewood et al. 2004; Huang et al. 2009a) and maize (Hochholdinger et al. 2004). In rice, the analysis of 313 nuclear-encoded mitochondrial proteins using four different algorithms revealed that the correct mitochondrial location was predicted in only $60 \%$ of cases (Huang et al. 2009a). The number of mitochondrial proteins predicted to be involved in the electron transport chain, tricarboxylic acid cycle and stress responses was well conserved between rice and Arabidopsis (Heazlewood et al. 2004; Huang et al. 2011). The relatively low predictive accuracy of the localization algorithms highlights the importance of experimental validation, particularly when attempting to target recombinant proteins to the mitochondria.

The best way to determine the activity of mitochondrial targeting peptides is to test them using a visible marker, such as enhanced green fluorescent protein (eGFP) adapted for optimal activity in plants 
(Chiu et al. 1996; Snapp 2005). This will confirm the potential suitability of the import sequence activity, although it does not guarantee the import of other proteins because the structure of the linked protein can also influence the efficiency of targeting peptides (Van Steeg et al. 1986). We therefore generated transgenic rice callus and plants in which nuclear-encoded recombinant eGFP was targeted to the mitochondria using six different mitochondrial N-terminal targeting peptides. These sequences were derived from diverse phylogenetic origins (higher and lower eukaryotes) and varied in their targeting probability scores, motifs and physicochemical properties. We analyzed the expression and localization of eGFP by immunoblot as well as confocal and electron microscopy in order to determine factors responsible for the effectiveness of mitochondrial targeting in rice.

\section{Materials and methods}

\section{Expression constructs}

We selected six different mitochondrial pre-sequences representing different phylogenetic origins. Two of the sequences were from the yeast Saccharomyces cerevisiae: the alpha subunit of the F1 sector of the mitochondrial F1F0 ATP synthase protein ATPA (NCBI: NP_009453.2) and the cytochrome oxidase subunit IV protein COX4 (NCBI: NP_011328.1). The third sequence was from the ascomycete fungus Neurospora crassa: subunit 9 of the mitochondrial ATPase protein, SU9 (NCBI: XM_954801.3). The other three sequences were from plants. Two were derived from dicot species: the Nicotiana plumbaginifolia F1-ATPase from the $\beta$-subunit protein MTS2 (NCBI: X02868.1) and the Arabidopsis thaliana $\gamma$ subunit of the mitochondrial ATP synthase pFA (NCBI: NM_128864.4). The final sequence represented the endogenous rice (Oryza sativa ssp. japonica) succinyl-CoA synthetase protein $\beta$-chain OsSCSb (NCBI: Q6K9N6).

The expression plasmids were generated using the MoClo cloning system (Weber et al. 2011) and an inhouse destination vector comprising the pUC57 vector backbone (GenScript, Piscataway, NJ, USA) joined to the cloning cassette of the Level 1 Position 2 MoClo vector $\mathrm{pICH} 47742$. The vector was amplified using primers 591 (5'-AAG CCC ACG AAG TGT GGG
GTG CCT AAT GAG TGA GCT AAC TCA CA-3') and $592\left(5^{\prime}\right.$-TTA ACA CAG AGT GGC CAG CCC CGA CAC CCG CCA ACA CCC G-3') and the 2200-bp AdeI digestion product was ligated to the 650-bp fragment released from pICH47742 by digestion with the same enzyme. The recombinant in-house vector (pUC57-L1P2) is available from Addgene (ID: 109221). All the Level 1 Position 2 plasmids were constructed using the strong constitutive maize ubiquitin-1 promoter including the first intron and the nopaline synthase (nos) terminator to control eGFP expression.

After MoClo restriction/ligation, $20 \mu \mathrm{l}$ of the reaction mix was used to transform Escherichia coli DH5 $\alpha$ competent cells. Positive clones were selected on lysogeny broth (LB) solid medium containing $100 \mu \mathrm{g} / \mathrm{ml}$ ampicillin (Sigma-Aldrich, Darmstadt, Germany), $20 \mu \mathrm{g} / \mathrm{ml}$ X-gal (Duchefa Biochemie, Haarlem, Netherlands) and $1 \mathrm{mM}$ isopropyl $\beta$-D-1thiogalactopyranoside (IPTG; Sigma-Aldrich). Plasmid DNA was extracted using the GenElute Plasmid Miniprep Kit (Sigma-Aldrich). The final constructs were named Ubi:SU9-eGFP-tNos, Ubi:COX4-eGFPtNos, Ubi:MTS2-eGFP-tNos, Ubi:pFA-eGFP-tNos, Ubi:ATPA-eGFP-tNos and Ubil:OsSCSb-eGFPtNos. The integrity of all plasmids was verified by sequencing (Macrogen, Madrid, Spain).

Transformation of rice callus and regeneration of transgenic plants

The six test vectors containing the individual mitochondrial targeting peptide sequences fused to eGFP were introduced separately into rice embryos, together with the hpt gene for selection as described by Christou et al. (1991) and Sudhakar et al. (1998). We selected five representative independent callus lines and corresponding regenerated plants for each construct for all subsequent analyses from among a population of at least 50 independent lines per construct.

Protein extraction and immunoblot analysis

Total rice protein extracts were prepared by grinding $0.1-0.2 \mathrm{~g}$ callus or leaf tissue in liquid nitrogen and thawing the powder in $0.2-0.4 \mathrm{~mL}$ of extraction buffer: $20 \mathrm{mM}$ Tris- $\mathrm{HCl} \mathrm{pH} 7.5,5 \mathrm{mM}$ ethylenediaminetetraacetic acid (EDTA), 0.1\% Tween-20, 0.1\% sodium dodecylsulfate (SDS), $2 \mathrm{mM}$ 
phenylmethanesulfonylfluoride (PMSF). The mixture was vortexed for $1 \mathrm{~h}$ at $4{ }^{\circ} \mathrm{C}$. Cell debris was removed by centrifugation at $15,000 \times g$ for $20 \mathrm{~min}$ at $4{ }^{\circ} \mathrm{C}$, and the supernatant was collected and stored at $-80{ }^{\circ} \mathrm{C}$. The protein concentration in the supernatants was determined using the Bradford method (AppliChem, Darmstadt, Germany). We fractionated $80 \mu \mathrm{g}$ of total rice protein by denaturing SDS-PAGE in polyacrylamide gels containing $10 \%$ SDS at $200 \mathrm{~V}$ for $60 \mathrm{~min}$, and then electro-transferred the protein to an Immobilon FL polyvinylidene difluoride (PVDF) membrane (Merck, Darmstadt, Germany) using a semidry transfer apparatus (Bio-Rad, Hercules, CA, USA) at $20 \mathrm{~V}$ for $45 \mathrm{~min}$. The membrane was immersed in 5\% non-fat milk in Tris-buffered saline with Tween-20 (TBST) solution (0.2 M Tris- $\mathrm{HCl} \mathrm{pH}$ 7.6, $1.37 \mathrm{M} \mathrm{NaCl}, 0.1 \%$ Tween-20) for $1 \mathrm{~h}$ at room temperature. Membranes were incubated with antieGFP polyclonal antibody SAB4301138 (SigmaAldrich) diluted 1:2000 in 5\% non-fat milk in TBST overnight at $4{ }^{\circ} \mathrm{C}$, then rinsed three times for $10 \mathrm{~min}$ in TBST. The membranes were subsequently incubated with an alkaline phosphatase-conjugated goat antirabbit secondary antibody (Sigma-Aldrich) (diluted 1:5000 in 2\% non-fat milk in TBS-T) for $1 \mathrm{~h}$ at room temperature followed by three $10 \mathrm{~min}$ rinses in TBST. Signals were detected using SIGMAFAST BCIP/ NBT tablets (Sigma-Aldrich).

\section{Confocal microscopy}

We used confocal microscopy to confirm the localization of eGFP in small pieces of rice callus $\left(1 \mathrm{~mm}^{3}\right)$ or leaf tissue $(1 \times 10 \mathrm{~mm})$ after incubation with the mitochondrial counterstain Mitotracker Red (Molecular Probes/Invitrogen, Paisley, UK) according to the manufacturer's recommendations. The tissues were then fixed with $2 \%$ paraformaldehyde in $0.1 \mathrm{M}$ sodium phosphate buffer ( $\mathrm{pH}$ 7.2) and cut into semithin sections (30-40 $\mu \mathrm{m})$ using a CM3050S Research Cryostat (Leica Microsystems, Wetzlar, Germany). The sections were collected on standard glass microscope slides pre-coated with poly-L-lysine and images were captured using an FV1000 laser scanning confocal microscope (Olympus, Hamburg, Germany) with illumination at $488 \mathrm{~nm}$ (excitation wavelength of eGFP, multiline argon laser) and $559 \mathrm{~nm}$ (excitation wavelength of Mitotracker Red, diode laser). Five different callus lines and leaves (biological replicates) were analyzed per targeting peptide, and the percentage of merged mitochondria (where the green and red color signals co-localized) was counted in a minimum of three images taken from different areas/sections in each sample to determine the mitochondrial targeting efficiency of each peptide.

\section{Immuno-electron microscopy}

Small callus and leaf samples as described above were fixed in $1 \%$ glutaraldehyde and $1 \%$ paraformaldehyde in $0.1 \mathrm{M}$ sodium phosphate buffer $(\mathrm{pH}$ 7.2) for $16-24 \mathrm{~h}$ at $4{ }^{\circ} \mathrm{C}$ and washed three times $(10 \mathrm{~min})$ with the same buffer. After fixation, samples were dehydrated in an ethanol series (30-100\%) before embedding in Lowicryl K4 M resin (Polysciences, Hirschberg an der Bergstrasse, Germany) in a cold chamber at -20 to $-35{ }^{\circ} \mathrm{C}$ and inducing polymerization by exposure to ultraviolet light.

Semithin $(2 \mu \mathrm{m})$ and ultrathin $(70-90 \mathrm{~nm})$ sections were prepared using a Reichert-Jung ultra-cut E cryotome (Leica Microsystems). The sections were stained with Richardson's blue, covered with a drop of DPX slide mounting medium and a coverslip, and observed under a DM4000B microscope (Leica Microsystems). Images were captured using a DFC300 FX 1.4-MP digital color camera equipped with LAS v3.8 (Leica Microsystems). The ultrathin sections were mounted on Formvar carbon-coated gold grids (200 mesh) and incubated for $15 \mathrm{~min}$ in blocking buffer for polyclonal antibodies (200 mM Tris- $\mathrm{HCl} \mathrm{pH} 7.4,1 \%$ Tween-20, $0.1 \%$ gelatin, $1 \%$ BSA) or monoclonal antibodies (10 mM Tris-HCl pH 7.4, $0.9 \% \mathrm{NaCl}, 0.05 \%$ PEG 20,000, 3\% BSA). The grids were then washed in distilled water and incubated overnight at $4{ }^{\circ} \mathrm{C}$ with primary polyclonal anti-eGFP antibody PA5-22688 (Thermo Fisher Scientific, Waltham, MA, USA) diluted 1:200 in blocking buffer, or primary monoclonal anti-eGFP antibody 11814460001 (Sigma-Aldrich) diluted 1:500 in blocking buffer. We cross-adsorbed the polyclonal antibody following the protocol of Deena and Fletcher (1993). After washing in distilled water, followed by a further 30-min incubation in the appropriate blocking buffer and another wash, the grids were incubated at room temperature for $1 \mathrm{~h}$ with the 15-nm gold-conjugated secondary antibody diluted 1:20 in the appropriate blocking buffer: goat-anti-rabbit IgG for the polyclonal antibody, or EM-grade goat-anti-mouse IgG for 
the monoclonal antibody (Electron Microscopy Sciences, Hatfield, PA, USA). Finally, the grids were contrasted with $1 \%$ uranyl acetate in water $(20 \mathrm{~min})$ and Reynold's lead citrate ( $2 \mathrm{~min}$ ) before observation in an EM 910 Transmission Electron Microscope (Zeiss, Oberkochen, Germany). We analyzed at least two grids per treatment and sample (callus or leaf tissue). More than 10 areas containing mitochondria were registered per treatment.

\section{Bioinformatics}

Targeting peptide cleavage sites, probability scores and physicochemical properties were determined using MitoFates (http://mitf.cbrc.jp/MitoFates/ cgibin/top.cgi), MitoProt (https://ihg.gsf.de/ihg/ mitoprot.html) and TPpred v3.0 (https://tppred3. biocomp.unibo.it/ tppred3) (Claros and Vincens 1996; Fukasawa et al. 2015; Savojardo et al. 2015).

\section{Results}

Probability scores and recognition motifs of selected mitochondrial targeting peptides

We selected six mitochondrial targeting peptides for analysis (ATPA, COX4, SU9, MTS2, pFA and OsSCSb), whose properties and phylogenetic origins are summarized in Table 1. Bioinformatics analysis revealed that all six targeting peptides are positively charged and achieve high targeting probability scores but feature different numbers of Tom 20 recognition motifs and N-terminal hexamer motifs, as described by Fukasawa et al. (2015). Hexamer motifs are enhancer motifs that interact with hydrophobic binding pockets on the Tom 20 receptor and improve mitochondrial targeting effectiveness and accuracy (Obita et al. 2003; Fukasawa et al. 2015). The structural relationships among the various motifs are shown in Fig. 1.

\section{Expression of eGFP in rice}

The six mitochondrial targeting peptides we tested included three with single predicted cleavage sites (ATPA, COX4 and OsSCSb) and three with dual predicted cleavage sites (SU9, MTS2 and pFA) based on combined analysis using three bioinformatics programs: MitoFates, MitoProt and TPpred. The six recombinant eGFP constructs were expressed in rice. The callus and leaf extracts were analyzed by immunoblot to determine the size of the recovered eGFP products (Fig. 2). The mature eGFP has a molecular weight of $27 \mathrm{kDa}$, but all six targeting peptides have internal cleavage sites leaving a remnant on the processed protein, so we anticipated the mature processed products would be somewhat higher in molecular weight than native eGFP, depending on the length of the remnant (Fig. 1). The ATPA, COX4 and OsSCSb variants of eGFP yielded bands of $\sim 28$ $\mathrm{kDa}$, consistent with successful cleavage of the targeting peptide and the presence of a remnant ranging in length from 11 to 14 residues. The SU9

Table 1 Characteristics of the six mitochondrial targeting peptides

\begin{tabular}{|c|c|c|c|c|c|c|}
\hline Peptide & Source & $\begin{array}{l}\text { Targeting } \\
\text { probability (\%) }\end{array}$ & $\begin{array}{l}\text { Size } \\
\text { (aa) }\end{array}$ & $\begin{array}{l}\text { Predicted cleavage } \\
\text { position (aa) }\end{array}$ & $\begin{array}{l}\text { No. of Tom } 20 \\
\text { recognition motifs }\end{array}$ & $\begin{array}{l}\text { No. of N-terminal } \\
\text { hexamer motifs }\end{array}$ \\
\hline ATPA & $\begin{array}{l}\text { Saccharomyces } \\
\text { cerevisiae }\end{array}$ & 99 & 35 & 24 & 0 & 4 \\
\hline $\mathrm{COX} 4$ & $\begin{array}{l}\text { Saccharomyces } \\
\text { cerevisiae }\end{array}$ & 92 & 29 & 17 & 0 & 1 \\
\hline SU9 & $\begin{array}{l}\text { Neurospora } \\
\text { crassa }\end{array}$ & 98 & 69 & $35 / 67$ & 2 (ASRLA, AVRVA) & 3 \\
\hline MTS2 & $\begin{array}{l}\text { Nicotiana } \\
\text { plumbaginifolia }\end{array}$ & 97 & 87 & $37 / 42$ & 1 (LNRAV) & 0 \\
\hline $\mathrm{pFA}$ & $\begin{array}{l}\text { Arabidopsis } \\
\text { thaliana }\end{array}$ & 97 & 77 & $30 / 42$ & 2 (ITKAM, AMKMV) & 1 \\
\hline OsSCSb & $\begin{array}{l}\text { Oryza sativa ssp. } \\
\text { japonica }\end{array}$ & 86 & 27 & 13 & 2 (LGKLA, ASRAL) & 2 \\
\hline
\end{tabular}




\begin{tabular}{|c|c|c|}
\hline $\begin{array}{l}\text { Targeting } \\
\text { peptide }\end{array}$ & $\begin{array}{c}\text { Net } \\
\text { charge }\end{array}$ & Targeting peptide amino acid sequence \\
\hline ATPA & 0.208 & $\begin{array}{l}\text { MLARTAAIRSLSRTLINSTKAARPAAAALASTRRL } \\
\frac{\phi \phi \beta \sigma \phi \phi}{\phi \phi \phi \beta \sigma \phi \phi \phi \beta \sigma \phi \sigma} \\
\frac{\phi \phi \phi \beta \sigma \phi}{\phi}\end{array}$ \\
\hline SU9 & 0.200 & $\begin{array}{l}\text { MASTRVLASRLASQMAASAKVARPAVRVAQVSKRTIQTGSPLQTLKRTQMTSIVNATTRQAFQKRAY YSS } \\
\frac{\phi \phi \sigma \beta \phi \phi}{\phi \sigma \beta \phi \phi \sigma}\end{array}$ \\
\hline MTS2 & 0.189 & 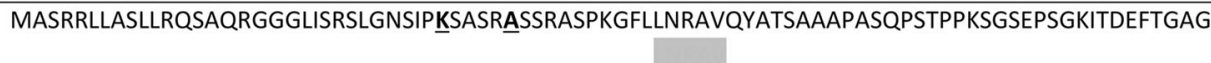 \\
\hline pFA & 0.071 & $\begin{array}{l}\text { MAMAVFRREGRRLLPSIAARPIAAIRSPLSSDQEEGLLGVRSISTQVVRNRMKSVKNIQKITKAMKMVAASKLRAVQ } \\
\phi \phi \phi \phi \beta \beta\end{array}$ \\
\hline cox4 & 0.235 & 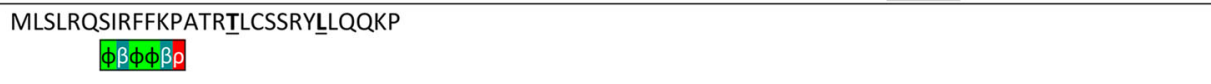 \\
\hline OsSCSb & 0.231 & $\begin{array}{l}\text { MVRGSLGKLASRALSVAGKWQGHQQLRR } \\
\qquad \frac{\phi \phi \sigma \beta \phi \phi}{\phi \sigma \beta \phi \phi \sigma}\end{array}$ \\
\hline
\end{tabular}

Fig. 1 Properties of targeting peptides and the structural relationships among the various motifs. N-terminal hexamer motifs are described using the following symbols to denote groups of amino acids: $\varphi=$ hydrophobic $(\mathrm{L}, \mathrm{F}, \mathrm{I}, \mathrm{V}, \mathrm{W}, \mathrm{Y}, \mathrm{M}, \mathrm{C}$

variant of eGFP yielded a $\sim 27 \mathrm{kDa}$ band, consistent with cleavage at position 67 of 69 and the presence of a comparatively small dipeptide remnant. For these four constructs, we therefore observed complete and successful cleavage of the targeting peptide in rice. The pFA sequence has predicted cleavage sites at positions 30 and 42 of 77, which should leave a remnant of at least 35 amino acids. Here we observed three distinct bands of $\sim 28, \sim 30$ and $\sim 32 \mathrm{kDa}$. The 30 and $32 \mathrm{kDa}$ bands reflected the anticipated sizes of the processed forms of pFA generated by cleavage at the predicted processing sites, whereas the other band indicated that the peptide is also cleaved closer to the native end of the eGFP than expected based on the predictions. Finally, the MTS2 targeting peptide has predicted cleavage sites at positions 37 and 42 of 87 , but the $\sim 35 \mathrm{kDa}$ band we detected indicated that neither site was cleaved successfully (Fig. 2).

Localization of eGFP in rice and the effectiveness of the targeting peptides

Having established that five of the six peptides were partially or fully cleaved, we analyzed the localization or $\mathrm{A}), \beta=\operatorname{basic}(\mathrm{R}, \mathrm{K}$ or $\mathrm{H}), \alpha=\operatorname{acidic}(\mathrm{E}, \mathrm{D}), \sigma=\operatorname{polar}(\mathrm{S}, \mathrm{T}$, $\mathrm{N}$ or $\mathrm{Q}$ ), and $\rho=$ secondary structure breaker (P or G). Gray boxes indicate Tom 20 recognition motifs. Underlined amino acids are predicted cleavage sites

of eGFP in rice callus (Fig. 3) and in the leaves of the corresponding regenerated plants (Fig. 4) by confocal microscopy. The penetration of the Mitotracker Red marker was more effective in callus than in leaves giving clearer results, but in both cases the green fluorescence of the eGFP and the red fluorescence of the Mitotracker Red marker co-localized in more than $70 \%$ of the merged images of tissues transformed with the ATPA, COX4, SU9, pFA and OsSCSb variants of eGFP, whereas the two signals were co-localized in fewer than $15 \%$ of the merged images of tissues transformed with the MTS2-eGFP construct. Immunogold labeling was carried out in callus and leaf tissue expressing four of the six constructs (two with the correct, anticipated cleavage patterns as well as pFA with the additional cleavage product and MTS2 which did not show evidence of cleavage). The 15-nm gold particles were strongly associated with the inner mitochondrial membrane and/or mitochondrial matrix in callus (Fig. 5) and leaf (Fig. 6) tissues transformed with the COX4, SU9 and pFA variants, whereas in tissues transformed with the MTS2-eGFP construct the labeling was mostly restricted to the cytosol. For all four targeting peptides, we also observed strongly- 


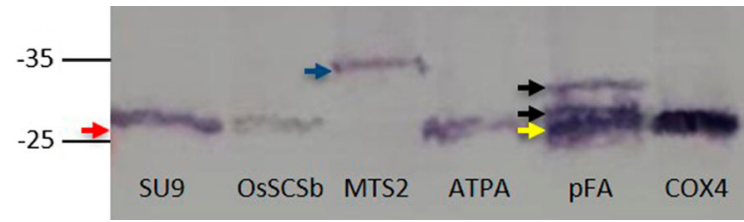

Fig. 2 Analysis of six constructs targeting the mitochondria in rice (SU9-eGFP, OsSCSb-eGFP, MTS2-eGFP, ATPA-eGFP, pFA-eGFP and COX4-eGFP) by denaturing SDS-PAGE and western blot. The results represent transformed callus lines but identical profiles were seen in the leaves of transgenic plants. The red arrow $(\sim 27 \mathrm{kDa})$ indicates the molecular weight of correctly processed eGFP. The blue arrow $(\sim 35 \mathrm{kDa})$ indicates eGFP with a non-cleaved MTS2 peptide. The black arrows ( $\sim 30$ and $\sim 32 \mathrm{kDa}$ ) indicate the products generated following the correct processing of the pFA peptide and the yellow arrow $(\sim 28 \mathrm{kDa}$ ) indicates cleavage closer to the native end of the eGFP

labeled protein bodies in the cytosol (Fig. 7), which is consistent with earlier observations of GFP-prolamin fusions in rice (Saito et al. 2009; Shigemitsu et al. 2013). These signals most likely represent eGFP aggregates, which we detected in the vacuoles of callus and leaf tissues expressing each of the four constructs (Fig. 7). The ectopic formation of protein bodies in the leaves is likely to reflect our use of a strong, constitutive promoter (Saberianfar et al. 2016). The aggregates were larger in callus samples expressing MTS2-eGFP compared to those expressing the COX4, SU9 and pFA variants (Supplementary Figs. 1 and 2). Very occasionally, we observed non-specific labeling of the nucleus and chloroplasts in tissues expressing each of the four constructs (Supplementary Figs. 3 and 4).

\section{Discussion}

Proteins targeted for mitochondrial import may be directed to the inner matrix, the inner or outer membranes, or the intermembrane space (Chacinska et al. 2009; Weis et al. 2013). Most mitochondrial proteins are encoded by the nuclear genome, synthesized on cytosolic ribosomes and ultimately translocated to the appropriate sub-mitochondrial location (Taylor and Pfanner 2004; Dolezal et al. 2006). The mechanism that controls protein import into mitochondria involves an $\mathrm{N}$-terminal pre-sequence or targeting peptide which directs the protein to the correct internal location, and the peptide is removed by proteolytic cleavage when the protein reaches its destination (Huang et al. 2009a; Carrie et al. 2015).

Mitochondrial targeting peptides tend to feature a high content of hydrophobic and positively charged amino acid residues, a near absence of negatively charged residues, and a very low abundance of acidic amino acids (Berglund et al. 2009). Mitochondrial presequences have the tendency to form an amphiphilic $\alpha$-helix, which interacts with the import receptor Tom20 (Pfanner and Geissler 2001; Endo and Kohda 2002), a $20-\mathrm{kDa}$ subunit of the outer mitochondrial membrane complex translocase (Saitoh et al. 2007). Tom 20 recognizes the same motifs in plants and yeast, conventionally represented as $\varphi x x \varphi \varphi$ (where $\varphi$ is a hydrophobic amino acid and $\mathrm{x}$ is any amino acid). However, there are significant differences in the topology, localization, amino acid variations, binding motifs and number of Tom 20 proteins in different organisms (Obita et al. 2003; Saitoh et al. 2007).

The Tom 20 protein in fungi and animals is anchored via its $\mathrm{N}$-terminus to the mitochondrial outer membrane and therefore exposes its C-terminal domain to the cytosol. In contrast, Tom 20 in plants is anchored to mitochondria via its C-terminus and the $\mathrm{N}$-terminal domain is exposed. Accordingly, plant Tom 20 proteins are not orthologous to those of fungi and animals, and plant mitochondria also lack the other two receptor components that have been functionally characterized in yeast and mammalian systems, namely Tom70 and Tom22 (Macasev et al. 2004; Lister et al. 2007; Huang et al. 2009a; Rimmer et al. 2011). Previous studies have shown that plant Tom 20 proteins interact with the amino acid domains LRTLA and LRRFV in rice superoxide dismutase and Arabidopsis threonyl tRNA synthetase (Zhang et al. 2010). Even though Tom 20 recognition motifs have been well characterized, they are not essential for mitochondrial protein import (Mukhopadhyay et al. 2006; Lister et al. 2007; Lee et al. 2012). For example, when the Tom 20 recognition site of pFA was deleted, this reduced the efficiency of mitochondrial import in Arabidopsis by only 20\% (Lee et al. 2012). However, there are four Tom 20 paralogs in the Arabidopsis genome, three of which are known to be functional, whereas rice (like yeast) has only a single Tom 20 gene (Lister et al. 2007). Despite the major differences between Tom 20 proteins in plants and fungi, mitochondrial targeting peptides from yeast and filamentous fungi are functional in plants. We tested three 


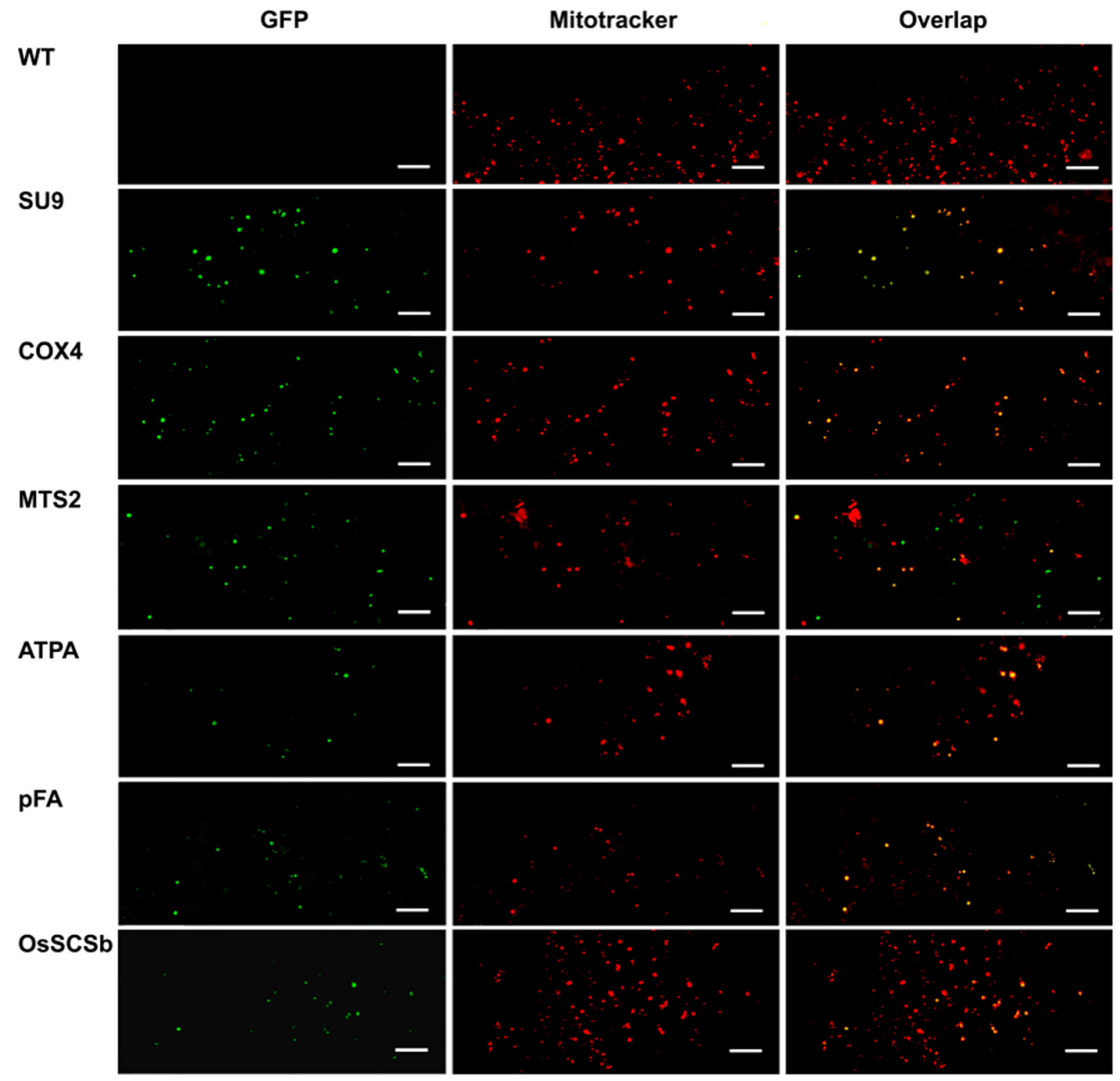

Fig. 3 Confocal laser scanning microscopy images of wildtype (WT) rice callus and callus lines transformed with eGFP constructs linked to the SU9, COX4, MTS2, ATPA, pFA and OsSCSb mitochondrial targeting peptides. The three columns show the individual signals for eGFP (green fluorescence) and Mitotracker Red (red fluorescence) and the overlap (merged confocal image mixing green and red fluorescence) (bars $=20$

such peptides, namely ATPA and COX4 from $S$. cerevisiae and SU9 from N. crassa. Previously, all three peptides have been shown to successfully direct recombinant proteins to mitochondria in yeast, tobacco and Arabidopsis (Nelson et al. 2007; Burén et al. 2017; Pérez-González et al. 2017) and similarly $\mu \mathrm{m})$. Five different callus lines and leaves (biological replicates) were analyzed per targeting peptide, and the percentage of merged mitochondria (where the green and red color signals colocalized) was counted in a minimum of three images taken from different areas/sections in each sample to determine the mitochrondrial targeting efficiency of each peptide

we found that all three were able to direct eGFP to the mitochondria in rice. Interestingly, only one of these peptides features a Tom20-recognition motif but all three contain N-terminal hexamers. This provides more evidence that Tom20-recognition motifs are not strictly required for mitochondrial import in plants. 


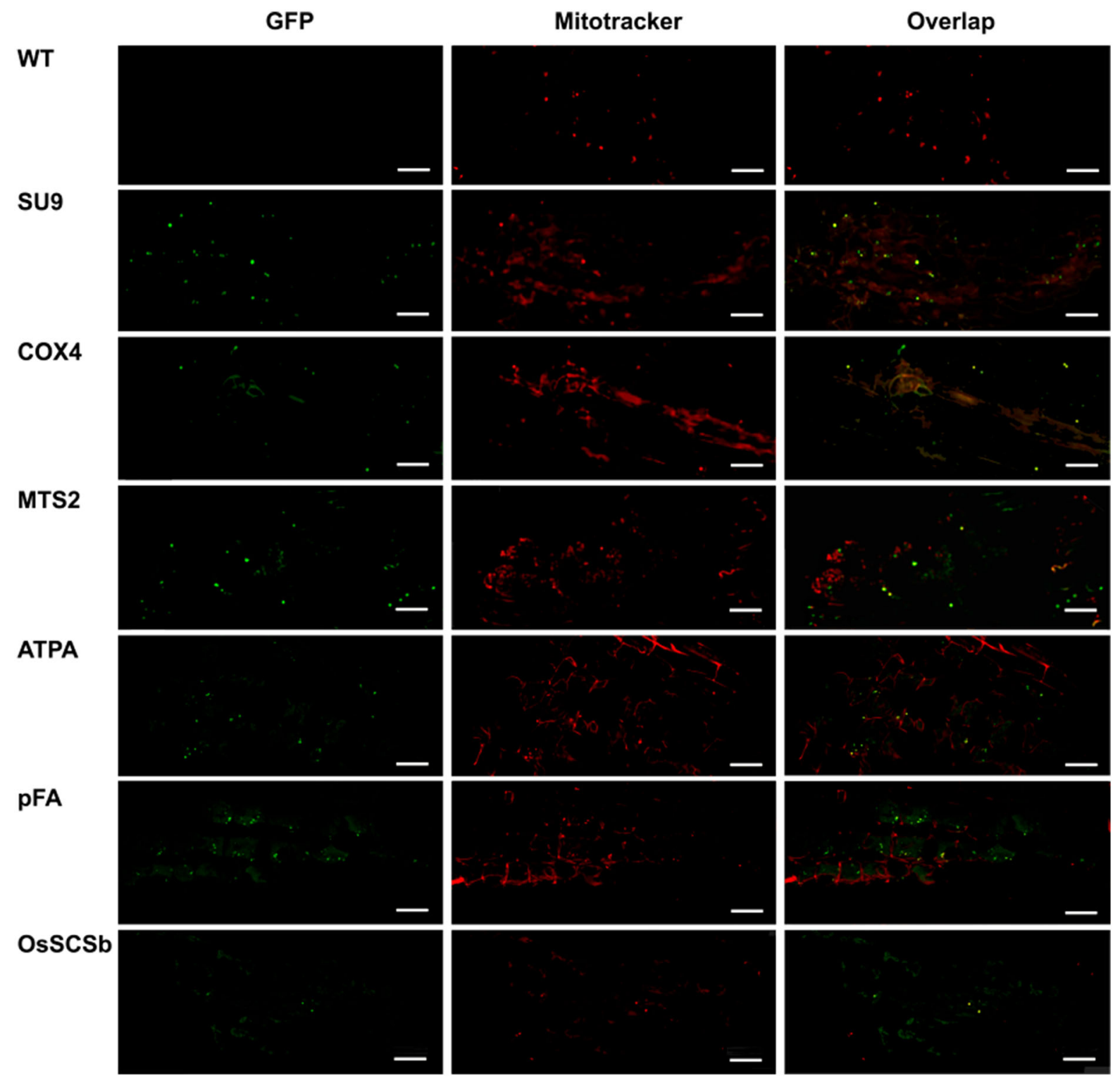

Fig. 4 Confocal laser scanning microscopy images of wildtype (WT) rice leaves and leaves from transgenic lines transformed with eGFP constructs linked to the SU9, COX4, MTS2, ATPA, pFA and OsSCSb mitochondrial targeting

We also tested three plant-derived targeting peptides, including the Arabidopsis pFA sequence which was mentioned briefly above. The others were the OsSCSb peptide from rice and the MTS2 sequence from N. plumbaginifolia. Lee et al. (2012) showed that Arabidopsis pFA contains multiple sequence motifs that target different mitochondrial compartments. In addition to the IAARP Tom20-recognition motif, the peptides. The three columns show the individual signals for eGFP (green fluorescence) and Mitotracker Red (red fluorescence) and the overlap (merged confocal image mixing green and red fluorescence) (bars $=20 \mu \mathrm{m}$ )

sequences DQEEG and VVRNR are involved in translocation across the mitochondrial membrane, and the sequences RLLPS and SISTQ pull proteins into the matrix. In another study, the Arabidopsis pFA peptide efficiently imported 16 nitrogenase protein components into the mitochondrial matrix of Nicotiana benthamiana in transient expression experiments, as well as a GFP fusion protein. A $\sim 30 \mathrm{kDa}$ 


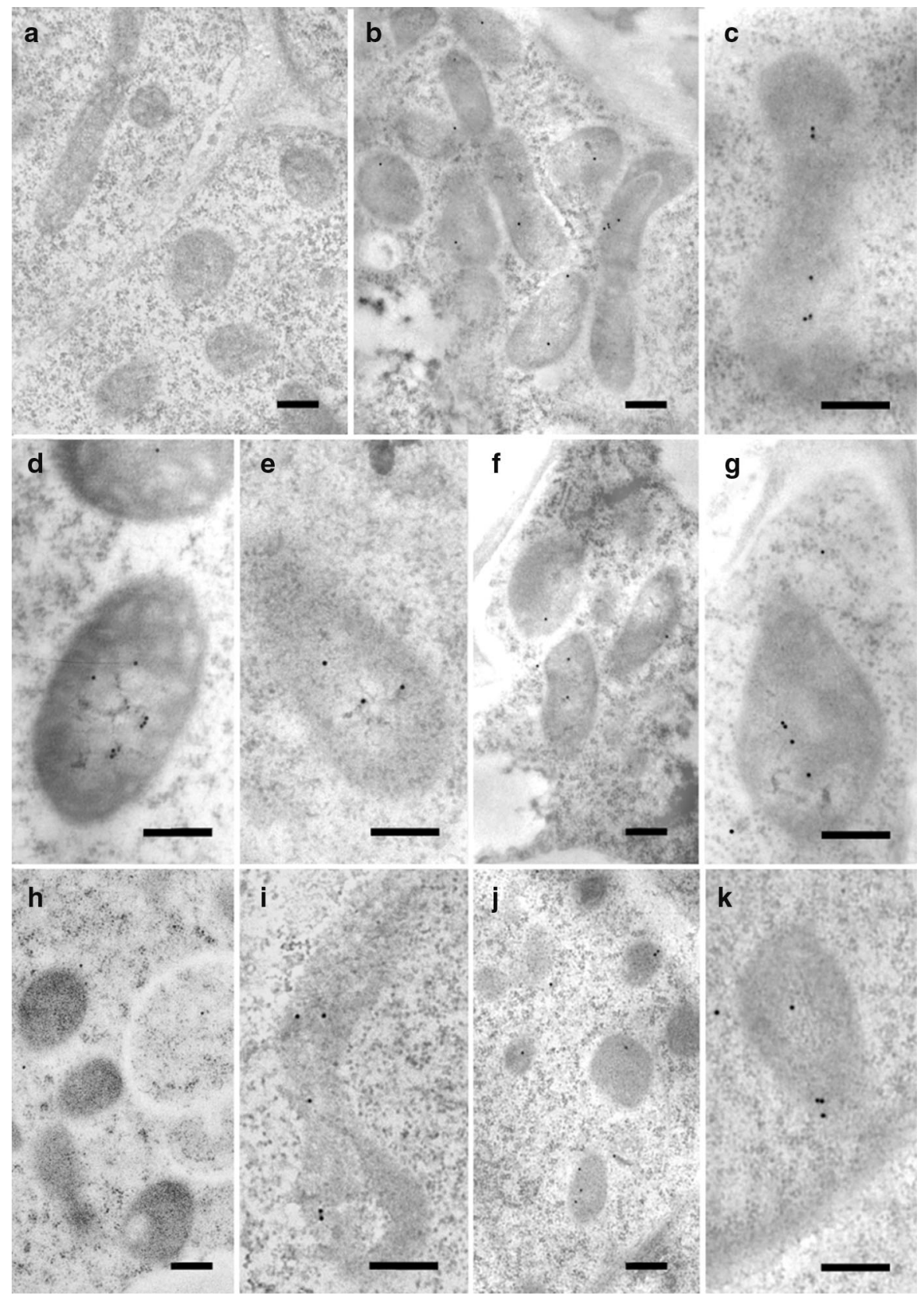

Fig. 5 Immunogold labeling of eGFP in the mitochondria of rice callus cells using a GFP-specific monoclonal antibody (diluted 1:200) (a-c, f-k) or eGFP polyclonal antibody (diluted 1:500) ( $\mathbf{d}=$ non-cross adsorbed, $\mathbf{e}=$ cross-adsorbed). Monoclonal antibodies were used to confirm the localization profile revealed by the cross-adsorbed polyclonal antibody although the signal produced by the monoclonal antibody was weaker.

band was observed corresponding to the correctly processed GFP as well as a less abundant $\sim 28 \mathrm{kDa}$ band representing an alternatively processed form or a a Wild-type cells. b-e SU9-eGFP (b, c = monoclonal antibody, $\mathbf{d}, \mathbf{e}=$ polyclonal antibody). $\mathbf{f}-\mathbf{g}$ Cox4-eGFP is also labeled outside the mitochondria. h-i MTS2-eGFP is labeled in only a few mitochondria but also in the cytosol. $\mathbf{j}-\mathbf{k}$ pFA-eGFP is labeled inside the mitochondria (bars $=200 \mathrm{~nm}$; gold particle size $=15 \mathrm{~nm}$ )

degradation product (Allen et al. 2017). Similarly, we found that the Arabidopsis pFA targeting peptide was sufficient for the mitochondrial import of eGFP in rice, 


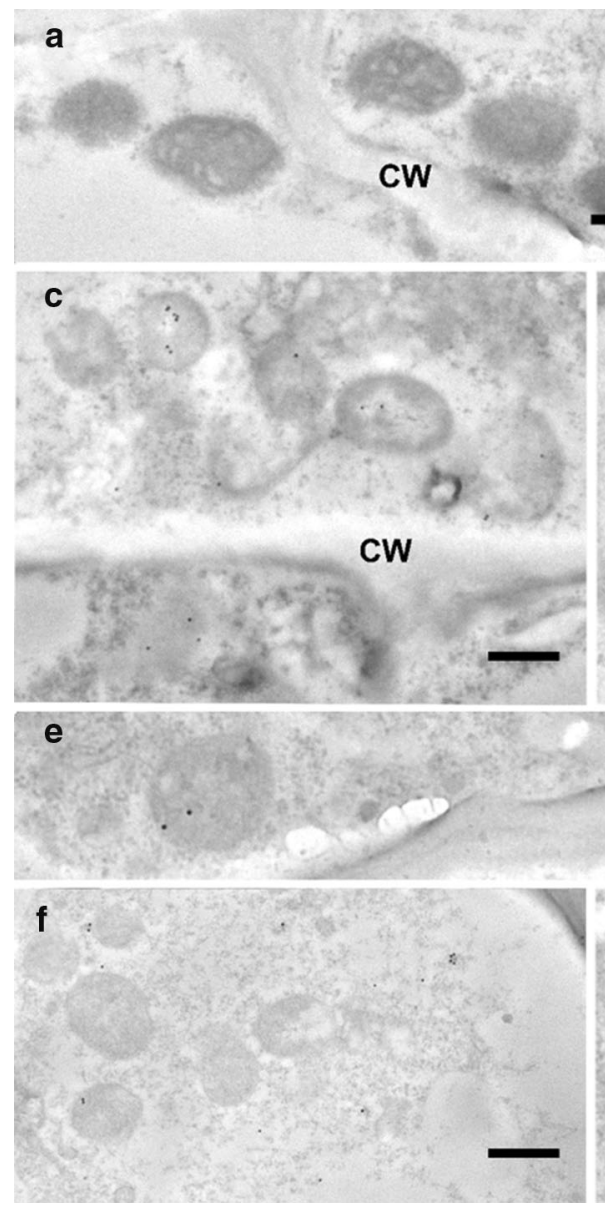

Fig. 6 Immunogold labeling of eGFP in the mitochondria of rice leaf cells using a GFP-specific monoclonal antibody (diluted 1:200). $\mathbf{a}-\mathbf{b}=$ wild-type, $\mathbf{c}-\mathbf{d}=$ SU9-eGFP, $\mathbf{e}=$ pFA-

yielding three different bands of $\sim 28, \sim 30$ and $\sim$ $32 \mathrm{kDa}$. Our bioinformatics analysis suggested that the 30 and $32 \mathrm{kDa}$ bands represented the expected processed forms of the pFA-eGFP fusion and the remaining band was an alternatively processed form or a degradation product. This strongly suggests that the pFA peptide works as effectively in rice (this study) as it does in dicot species (Lee et al. 2012; Allen et al. 2017). We tested the OsSCSb peptide based on an earlier report with tentative bioinformatics and mass spectrometry data predicting its mitochondrial targeting ability (Huang et al. 2009b). Our empirical data supported this prediction by confirming the mitochondrial import of eGFP, the first time this sequence has been shown directly to function as a mitochondrial import peptide. Notably, both pFA and OsSCSb
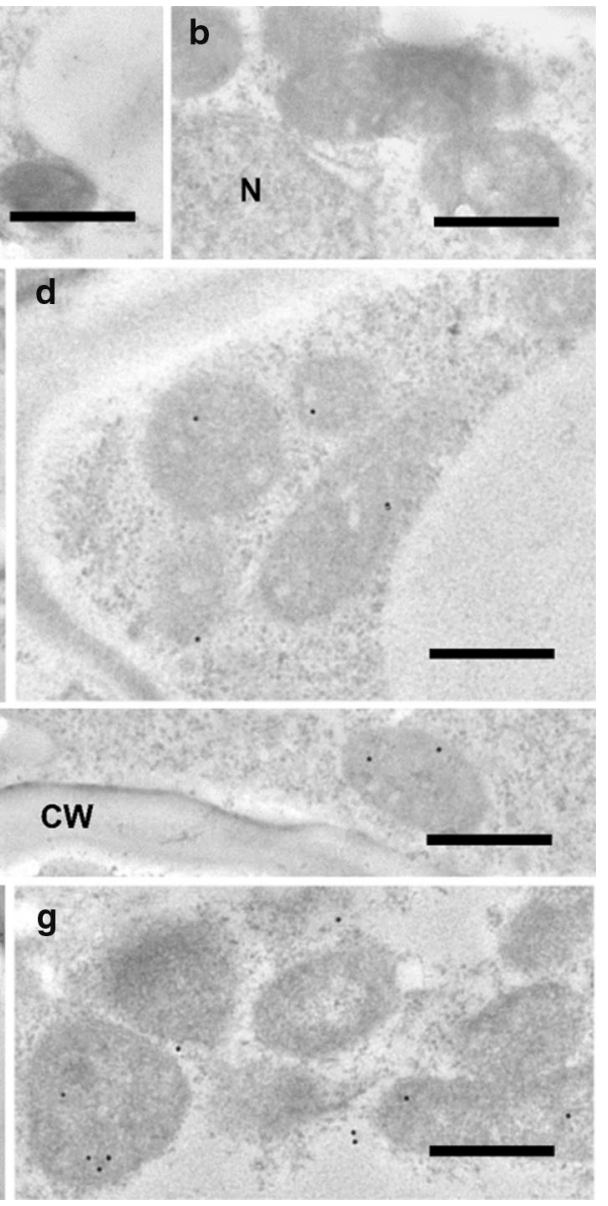

eGFP, $\mathbf{f}=$ MTS2-eGFP, $\mathbf{g}=$ Cox4-eGFP $(\mathrm{CW}=$ cell wall, $\mathrm{N}=$ nucleus; bars $=500 \mathrm{~nm}$; gold particle size $=15 \mathrm{~nm}$ )

contain Tom20-binding motifs and N-terminal hexamers.

The N. plumbaginifolia MTS2 sequence was one of the first mitochondrial targeting peptides to be characterized in plants and has been shown to work in tobacco, although the authors did not present detailed microscopic analysis (Boutry and Chua 1985; Chaumont et al. 1994). Surprisingly, we found that the MTS2 sequence appeared insufficient for the mitochondrial import of eGFP in rice, and immunoblot experiments provided evidence that the protein was not cleaved in rice cells. Among the six peptides we tested, MTS2 was the only one that contained at least one Tom20-binding motif but no N-terminal hexamers, indicating that the latter may be necessary for mitochondrial import in rice. Similarly, mutations in the N-terminal hexamers of potato formate 


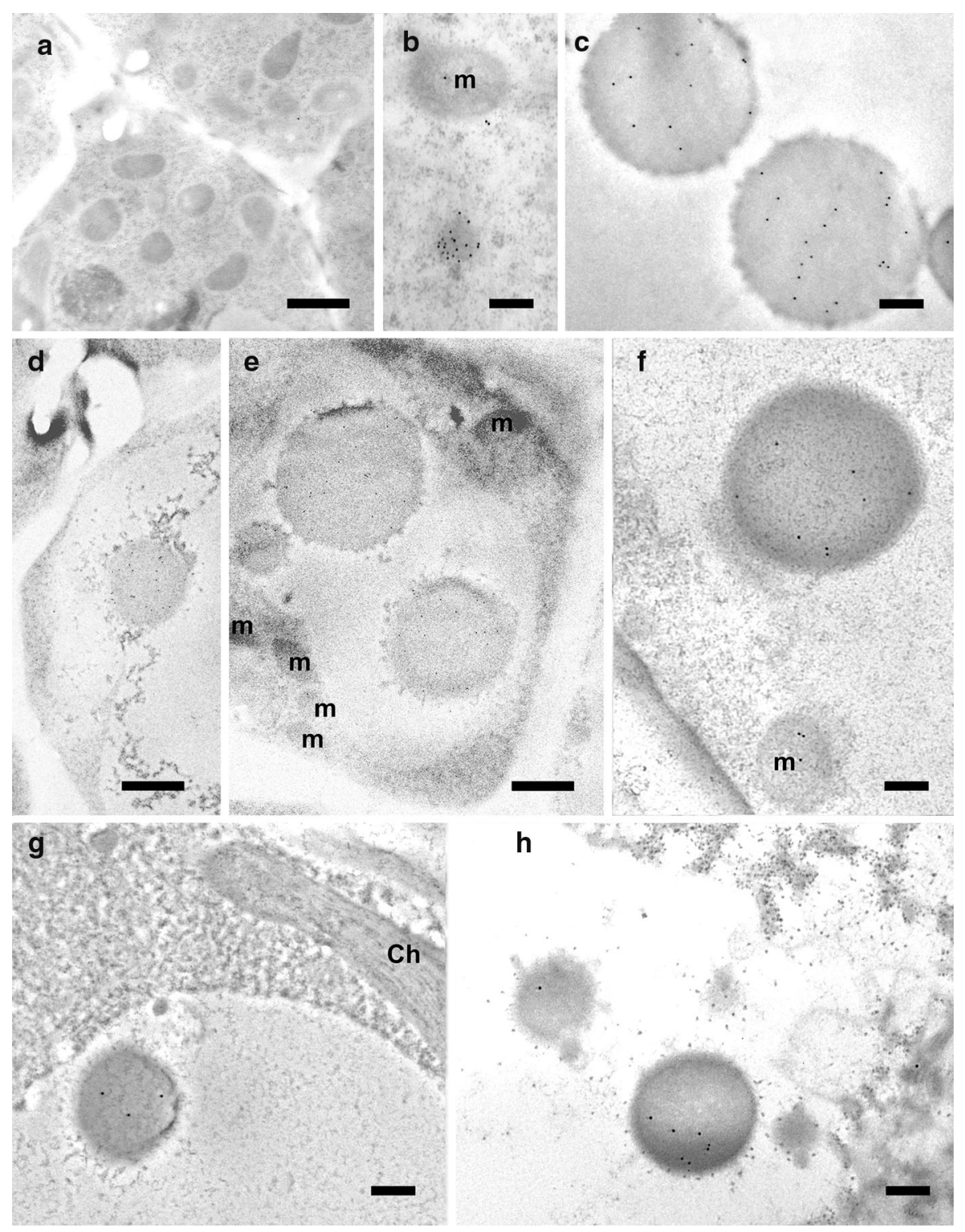

Fig. 7 Immunogold labeling of protein bodies in rice callus and leaf cells using a GFP-specific monoclonal antibody (diluted 1:200). a Wild-type negative control, showing no protein bodies. b Labeled protein body in the cytosol of callus cells expressing Cox4-eGFP. Labeled protein bodies in the vacuole of

dehydrogenase were previously shown to block the mitochondrial import of GFP fusion proteins (Ambard-Bretteville et al. 2003). In contrast, Gnanasambandam et al. (2008) showed in a transient expression system that the MTS2 peptide efficiently targeted GFP to mitochondria in several plants: five monocots (sugarcane, wheat, corn, sorghum and onion) and seven dicots (cucumber, cauliflower, tomato, callus cells (c) and leaf cells (g-h) expressing SU9-eGFP. de Large protein bodies close to (d) and inside (e) the vacuoles of callus cells expressing MTS2-eGFP. f Labeled protein body in callus cells expressing pFA-eGFP ( $\mathrm{m}=$ mitochondria; bars a, $\mathbf{g}$ and $\mathbf{h}=1 \mu \mathrm{m}, \mathbf{b}-\mathbf{f}=200 \mathrm{~nm} ;$ gold particle size $=15 \mathrm{~nm})$

capsicum, pumpkin, coriander and sunflower). The MTS2 peptide therefore appears to be strongly influenced by the choice of cargo protein and host species, and detailed microscopy should be carried out to confirm the correct targeting of recombinant proteins using this sequence.

Confocal microscopy alone may not be sufficient to draw definitive conclusions about the efficiency or 
accuracy of targeting peptides in stably transformed intact plants. Our confocal microscopy data indicated efficient mitochondrial import in rice callus and leaf tissues, but detailed analysis by immuno-electron microscopy revealed a certain level of non-specific labeling in the cytoplasm (Fig. 7). This may reflect the formation of protein body-like structures in response to the high levels of recombinant protein synthesis, as discussed by Gutierrez et al. (2013). Many previous studies have reported that protein bodies can be induced in rice and wheat callus and seeds (Arcalis et al. 2004; Saito et al. 2009; Takaiwa et al. 2009; Shigemitsu et al. 2013). Protein bodies do not usually form naturally in leaves, but they can be induced by the high-level expression of recombinant proteins, for example in N. benthamiana (Saberianfar et al. 2016). Protein bodies form mainly in the endoplasmic reticulum but may bud off into the cytosol as unattached organelles or may be removed to the vacuole (Levanony et al. 1992). In wheat, storage proteins aggregate into protein bodies and are then transported to the vacuoles without passing through the Golgi complex (Levanony et al. 1992).

We also observed non-specific labeling in the nucleus (Supplementary Fig. 3) and in the chloroplasts (Supplementary Fig. 4). The non-specific labeling in the nucleus is likely to be genuine, and probably occurs because eGFP is small enough $(\sim 27 \mathrm{kDa})$ to enter the nucleus by free bidirectional diffusion through the nuclear pore complex, which has a size exclusion limit of 40-60 kDa (Köhler et al. 1997; Wei et al. 2003; Seibel et al. 2007). The non-specific labeling in the chloroplast is more likely to be an experimental artifact. Berglund et al. (2009) previously reported that mitochondrial and chloroplast targeting peptides are similar enough that mitochondrial proteins can be inadvertently directed to the plastids. However, we found that the erroneous labeling of plastids could be eliminated by crossadsorbing the polyclonal antibody with wild-type leaf extract (Supplementary Fig. 4) suggesting that the fidelity of mitochondrial and plastid targeting in vivo is preserved.

\section{Conclusions}

Mitochondrial protein import is a complex, multistep process including the recognition of targeting peptides before translocation and peptide cleavage. $\mathrm{N}$-terminal hexamer motifs and Tom20-recognition motifs are thought to enhance mitochondrial targeting efficiency and accuracy. However, detailed analysis of the sequence motifs in each targeting peptide is necessary to understand the interactions between targeting peptides and translocator components during protein import. Here we demonstrated that the mitochondrial import of nuclear-encoded eGFP in rice requires only a single N-terminal hexamer motif whereas the Tom20-binding motifs are not strictly required, at least based on the evidence from the six targeting peptides we tested. The only one of six targeting peptides that did not function in rice in our experiments features a single Tom20-binding motif but lacks an N-terminal hexamer. The efficiency of mitochondrial import in rice is difficult to quantify but can be determined by combining stable gene expression with immunogold labeling to investigate in detail the subcellular localization of proteins targeted for mitochondrial import. Having tested a range of targeting peptides from fungi and plants, we conclude that the presence of particular functional motifs, specifically the N-terminal hexamer, is likely to be more important for successful mitochondrial import in rice than the phylogenetic origin of the targeting peptide.

Acknowledgements This work was supported by Bill and Melinda Gates Foundation Grant OPP1143172. CB was supported by a doctoral fellowship from AGAUR. XJ was supported by a doctoral fellowship from the Universidad Politecnica de Madrid.

Author's contribution $\mathrm{CB}, \mathrm{PC}, \mathrm{CZ}, \mathrm{EC}$ and LR designed the experiments. $\mathrm{CB}, \mathrm{VM}, \mathrm{APG}, \mathrm{AE}, \mathrm{XJ}$ carried out the experimental work. CB, VM, PC, CZ, EC and LR analyzed the data and wrote the paper. All authors reviewed and approved of the manuscript.

\section{Compliance with ethical standards}

Conflict of interest The authors declare that they have no conflict of interest.

Accession numbers Sequence data from this article can be found in National Center for Biotechnology Information (NCBI) under the following accession numbers: ATPA (NCBI: NP_009453.2), COX4 (NCBI: NP_011328.1), SU9 (NCBI: XM_954801.3), MTS2 (NCBI: X02868.1), pFA (NCBI: NM_128864.4), OsSCSb (NCBI: Q6K9N6).

Open Access This article is distributed under the terms of the Creative Commons Attribution 4.0 International License (http:// creativecommons.org/licenses/by/4.0/), which permits 
unrestricted use, distribution, and reproduction in any medium, provided you give appropriate credit to the original author(s) and the source, provide a link to the Creative Commons license, and indicate if changes were made.

\section{References}

Akopian D, Shen K, Zhang X, Shan S (2013) Signal recognition particle: an essential protein-targeting machine. Annu Rev Biochem 82:693-721

Allen RS, Tilbrook K, Warden AC, Campbell PC, Rolland V, Singh SP, Wood CC (2017) Expression of 16 nitrogenase proteins within the plant mitochondrial matrix. Front Plant Sci 8:1-14

Ambard-Bretteville F, Small I, Grandjean O, Colas Des FrancsSmall C (2003) Discrete mutations in the presequence of potato formate dehydrogenase inhibit the in vivo targeting of GFP fusions into mitochondria. Biochem Biophys Res Commun 311:966-971

Arcalis E, Marcel S, Altmann F, Kolarich D, Drakakaki G, Fischer R, Christou P, Stoger E (2004) Unexpected deposition patterns of recombinant proteins in post-endospermic reticulum compartments of wheat endosperm. Plant Physiol 136:3457-3466

Atkin OK, Macherel D (2009) The crucial role of plant mitochondria in orchestrating drought tolerance. Ann Bot 103:581-597

Bardel J, Louwagie M, Jaquinod M, Jourdain A, Luche S, Rabilloud T, Macherel D, Garin J, Bourguignon J (2002) A survey of the plant mitochondrial proteome in relation to development. Proteomics 2:880-898

Berglund $\mathrm{AK}$, Spånning E, Biverståhl H, Maddalo G, TellgrenRoth C, Mäler L, Glaser E (2009) Dual targeting to mitochondria and chloroplasts characterization of Thr-tRNA synthetase targeting peptide. Mol Plant 2:1298-1309

Boutry M, Chua N (1985) A nuclear gene encoding the beta subunit of the mitochondrial ATP synthase in Nicotiana plumbaginifolia. EMBO J 4:2159-2165

Brix J, Dietmeier K, Pfanner N (1997) Differential recognition of preproteins by the purified cytosolic domains of the mitochondrial import receptors Tom20, Tom22, and Tom70. J Biol Chem 272:20730-20735

Burén S, Jiang X, López-Torrejón G, Echavarri-Erasun C, Rubio LM (2017) Purification and in vitro activity of mitochondria targeted nitrogenase cofactor maturase NifB. Front Plant Sci 8:1567

Carrie C, Venne AS, Zahedi RP, Soll J (2015) Identification of cleavage sites and substrate proteins for two mitochondrial intermediate peptidases in Arabidopsis thaliana. J Exp Bot 66:2691-2708

Chacinska A, Koehler CM, Milenkovic D, Lithgow T, Pfanner $\mathrm{N}$ (2009) Importing mitochondrial proteins: machineries and mechanisms. Cell 138:628-644

Chaumont F, de Castro Silva Filho M, Thomas D, Leterme S, Boutry M (1994) Truncated presequences of mitochondrial F1- ATPase beta subunit from Nicotiana plumbaginifolia transport CAT and GUS proteins into mitochondria of transgenic tobacco. Plant Mol Biol 24:631-641
Chiu WL, Niwa Y, Zeng W, Hirano T, Kobayashi H, Sheen J (1996) Engineered GFP as a vital reporter in plants. Curr Biol 6:325-330

Christou P, Ford TL, Kofron M (1991) Genotype-independent stable transformation of rice (Oryza sativa L.) plants. Bio/ Technology 9:957-962

Claros MG, Vincens P (1996) Computational method to predict mitochondrially imported proteins and their targeting sequences. Eur J Biochem 241:779-786

Curatti L, Rubio LM (2014) Challenges to develop nitrogenfixing cereals by direct nif-gene transfer. Plant Sci 225:130-137

Deena E, Fletcher J (1993) Production of monospecific polyclonal antibodies against aster yellows mycoplasma like organism-associated antigen. Am Phytopathol Soc 83:1279-1282

Dolezal P, Likic V, Tachezy J, Lithgow T (2006) Evolution of the molecular machines for protein import into mitochondria. Science 313:314-318

Dudek J, Rehling P, van der Laan M (2013) Mitochondrial protein import: common principles and physiological networks. Biochim Biophys Acta Mol Cell Res 1833:274-285

Egea PF, Stroud RM, Walter P (2005) Targeting proteins to membranes: structure of the signal recognition particle. Curr Opin Struct Biol 15:213-220

Endo T, Kohda D (2002) Functions of outer membrane receptors in mitochondrial protein import. Biochim Biophys Acta 1592(1):3-14

Endo T, Yamano K, Kawano S (2011) Structural insight into the mitochondrial protein import system. Biochim Biophys Acta 1808:955-970

Fukasawa Y, Tsuji J, Fu SC, Tomii K, Horton P, Imai K (2015) MitoFates: improved prediction of mitochondrial targeting sequences and their cleavage sites. Mol Cell Proteom 14:1113-1126

Gnanasambandam A, Anderson DJ, Purnell MP, Nielsen LK, Brumbley SM (2008) The N-terminal presequence from F1-ATPase $\beta$-subunit of Nicotiana plumbaginifolia efficiently targets green fluorescent fusion protein to the mitochondria in diverse commercial crops. Funct Plant Biol 35:166-170

Gutierrez SP, Saberianfar R, Kohalmi SE, Menassa R (2013) Protein body formation in stable transgenic tobacco expressing elastin-like polypeptide and hydrophobin fusion proteins. BMC Biotechnol 13:40

Heazlewood JL, Tonti-Filippini JS, Gout AM, Day DA, Whelan J, Millar AH (2004) Experimental analysis of the Arabidopsis mitochondrial proteome highlights signaling and regulatory components, provides assessment of targeting prediction programs, and indicates plant-specific mitochondrial proteins. Plant Cell 16:241-256

Hochholdinger F, Guo L, Schnable PS (2004) Cytoplasmic regulation of the accumulation of nuclear-encoded proteins in the mitochondrial proteome of maize. Plant $\mathrm{J}$ 37:199-208

Huang J, Hack E, Thornburg RW, Myers AM (1990) A yeast mitochondrial leader peptide functions in vivo as a dual targeting signal for both chloroplast and mitochondria. Plant Cell 2:1249-1260

Huang S, Taylor NL, Narsai R, Eubel H, Whelan J, Millar AH (2009a) Experimental analysis of the rice mitochondrial 
proteome, its biogenesis, and heterogeneity. Plant Physiol 149:719-734

Huang S, Taylor NL, Whelan J, Millar AH (2009b) Refining the definition of plant mitochondrial presequences through analysis of sorting signals, N-terminal modifications, and cleavage motifs. Plant Physiol 150:1272-1285

Huang S, Millar AH, Taylor NL (2011) The plant mitochondrial proteome composition and stress response: conservation and divergence between monocots and dicots. In: Kempken F (ed) Advances in plant biology. Springer, New York, p 533

Kim DH, Hwang I (2013) Direct targeting of proteins from the cytosol to organelles: the ER versus endosymbiotic organelles. Traffic 14:613-621

Köhler RH, Zipfel WR, Webb WW, Hanson MR (1997) The green fluorescent protein as a marker to visualize plant mitochondria in vivo. Plant $\mathrm{J} 11: 613-621$

Kruft V, Eubel H, Jansch L, Werhahn W, Braun HP (2001) Proteomic approach to identify novel mitochondrial proteins in Arabidopsis. Plant Physiol 127:1694-1710

Lee S, Lee DW, Yoo Y, Duncan O, Oh YJ, Lee YJ, Lee G, Whelan J, Hwang I (2012) Mitochondrial targeting of the Arabidopsis F1-ATPase g-subunit via multiple compensatory and synergistic presequence motifs. Plant Cell 24:5037-5057

Levanony H, Rubin R, Altschuler Y, Galili G (1992) Evidence for a novel route of wheat storage proteins to vacuoles. J Cell Biol 119:1117-1128

Lill R, Mühlenhoff U (2008) Maturation of iron-sulfur proteins in eukaryotes: mechanisms, connected processes, and diseases. Annu Rev Biochem 77:669-700

Lister R, Carrie C, Duncan O, Ho LHM, Howell KA, Murcha MW, Whelan J (2007) Functional definition of outer membrane proteins involved in preprotein import into mitochondria. Plant Cell 19:3739-3759

López-Torrejón G, Jiménez-Vicente E, Buesa JM, Hernandez JA, Verma HK, Rubio LM (2016) Expression of a functional oxygen-labile nitrogenase component in the mitochondrial matrix of aerobically grown yeast. Nat Commun 7:11426

Luirink J, Sinning I (2004) SRP-mediated protein targeting: structure and function revisited. Biochim Biophys Acta Mol Cell Res 1694:17-35

Macasev D, Whelan J, Newbigin E, Silva-Filho MC, Mulhern TD, Lithgow T (2004) Tom22' an 8-kDa trans-site receptor in plants and protozoans, is a conserved feature of the TOM complex that appeared early in the evolution of eukaryotes. Mol Biol Evol 21:1557-1564

Mukhopadhyay A, Yang CS, Weiner H (2006) Binding of mitochondrial leader sequences to Tom 20 assessed using a bacterial two-hybrid system shows that hydrophobic interactions are essential and that some mutated leaders that do not bind Tom 20 can still be imported. Protein Sci 15:2739-2748

Nelson BK, Cai X, Nebenfu A (2007) A multicolored set of in vivo organelle markers for co-localization studies in Arabidopsis and other plants. Plant J 51:1126-1136

Obita T, Muto T, Endo T, Kohda D (2003) Peptide library approach with a disulfide tether to refine the Tom 20 recognition motif in mitochondrial presequences. J Mol Biol 328:495-504
Pérez-González A, Kniewel R, Veldhuizen M, Verma HK, Navarro-Rodríguez M, Rubio LM, Caro E (2017) Adaptation of the GoldenBraid modular cloning system and creation of a toolkit for the expression of heterologous proteins in yeast mitochondria. BMC Biotechnol 80:1-11

Pfanner N, Geissler A (2001) Versatility of the mitochondrial protein import machinery. Mol Cell Biol 2:339-349

Pierrel F, Cobine PA, Winge DR (2007) Metal ion availability in mitochondria. Biometals 20:675-682

Rasmusson AG, Soole KL, Elthon TE (2004) Alternative $\mathrm{Nad}(\mathrm{P}) \mathrm{H}$ dehydrogenases of plant mitochondria. Annu Rev Plant Biol 55:23-39

Rimmer KA, Foo JH, Ng A, Petrie EJ, Shilling PJ, Perry AJ, Mertens HD, Lithgow T, Mulhern TD, Gooley PR (2011) Recognition of mitochondrial targeting sequences by the import receptors Tom20 and Tom22. J Mol Biol 405:804-818

Saberianfar R, Sattarzadeh A, Joensuu JJ, Kohalmi SE, Menassa $\mathrm{R}$ (2016) Protein bodies in leaves exchange contents through the endoplasmic reticulum. Front Plant Sci 7:693

Saito Y, Kishida K, Takata K, Takahashi H, Shimada T, Tanaka K, Morita S, Satoh S, Masumura T (2009) A green fluorescent protein fused to rice prolamin forms protein bodylike structures in transgenic rice. J Exp Bot 60:615-627

Saitoh T, Igura M, Obita T, Ose T, Kojima R, Maenaka K, Endo T, Kohda D (2007) Tom20 recognizes mitochondrial presequences through dynamic equilibrium among multiple bound states. EMBO J 26:4777-4787

Savojardo C, Martelli PL, Fariselli P, Casadio R (2015) TPpred3 detects and discriminates mitochondrial and chloroplastic targeting peptides in eukaryotic proteins. Bioinformatics 31:3269-3275

Seibel NM, Eljouni J, Nalaskowski MM, Hampe W (2007) Nuclear localization of enhanced green fluorescent protein homomultimers, vol 368. Elsevier Inc., Amsterdam, pp 95-99

Shigemitsu T, Masumura T, Morita S, Satoh S (2013) Accumulation of rice prolamin-GFP fusion proteins induces ERderived protein bodies in transgenic rice calli. Plant Cell Rep 32:389-399

Sluse FE, Jarmuszkiewicz W, Navet R, Douette P, Mathy G, Sluse-Goffart CM (2006) Mitochondrial UCPs: new insights into regulation and impact. Biochim Biophys Acta Bioenerg 1757:480-485

Snapp E (2005) Design and use of fluorescent fusion proteins in cell biology. In: Bonafacino JS et al (eds) Current protocols in cell biology. Wiley, Hoboken, pp 21.4.1-21.4.13

Sudhakar D, Duc LT, Bong BB, Tinjuangjun P, Maqbool SB, Valdez M, Jefferson R, Christou P (1998) An efficient rice transformation system utilizing mature seed-derived explants and a portable, inexpensive particle bombardment device. Transgenic Res 7:289-294

Takaiwa F, Hirose S, Takagi H, Yang L, Wakasa Y (2009) Deposition of a recombinant peptide in ER-derived protein bodies by retention with cysteine-rich prolamins in transgenic rice seed. Planta 229:1147-1158

Taylor RD, Pfanner N (2004) The protein import and assembly machinery of the mitochondrial outer membrane. Biochim Biophys Acta Bioenerg 1658:37-43

Van Steeg H, Oudshoorn P, Van Hell B, Polman JE, Grivell LA (1986) Targeting efficiency of a mitochondrial pre- 
sequence is dependent on the passenger protein. EMBO J 5:3643-3650

Weber E, Engler C, Gruetzner R, Werner S, Marillonnet S (2011) A modular cloning system for standardized assembly of multigene constructs. PLoS ONE 6:e16765

Wei X, Henke VG, Strubing C, Brown EB, Clapham DE (2003) Real-time imaging of nuclear permeation by EGFP in single intact cells. Biophys J 84:1317-1327

Weis BL, Schleiff E, Zerges W (2013) Protein targeting to subcellular organelles via mRNA localization. Biochim Biophys Acta Mol Cell Res 1833:260-273

Wiedemann N, Pfanner N (2017) Mitochondrial machineries for protein import and assembly. Annu Rev Biochem 86:685-714

Yamamoto H, Itoh N, Kawano S, Yatsukawa YI, Momose T, Makio T, Matsunaga M, Yokota M, Esaki M, Shodai T,
Kohda D, Hobbs AE, Jensen RE, Endo T (2011) Dual role of the receptor Tom20 in specificity and efficiency of protein import into mitochondria. Proc Natl Acad Sci USA 108:91-96

Zhang Y, Baaden M, Yan J, Shao J, Qiu S, Wu Y (2010) The molecular recognition mechanism for superoxide dismutase presequence binding to the mitochondrial protein import receptor Tom 20 from Oryza sativa involves an LRTLA motif. J Phys Chem B 114:13839-13846

Publisher's Note Springer Nature remains neutral with regard to jurisdictional claims in published maps and institutional affiliations. 